\title{
LA ÉTICA EN LAS FINANZAS ISLÁMICAS
}

\author{
Armando Alvares GARCIA JÚNIOR*
}

\begin{abstract}
"Profesor de derecho internacional público, derecho del comercio internacional y sistemas jurídicos no occidentales (grado en derecho), estructura económica mundial, negocios internacionales y dirección estratégica y política de la empresa - I (grado ADE), dirección estratégica y política de la empresa - II (curso de adaptación ADE) y negociación y marketing internacional (MBAADE) en la Universidad Internacional de la Rioja, España.

armando.alvares@unir.net
\end{abstract}

Recebido em: 30/05/2014 - Aprovado em: 15/09/2014 - Disponibilizado em: 15/12/2014

RESUMEN: La falta de ética financiera de la banca occidental es un grave problema en la actualidad. En este artículo analizaremos la ética financiera bajo la Sharia, la ley islámica.

PALABRAS CLAVE: finanzas, banca, ética, Occidente, Islam

\section{Ethics in Islamic Finance}

ABSTRACT: The lack of financial ethics of Western Banking is a serious problem today. This article explores the financial ethics under Sharia, the Islamic law.

KEYWORDS: finance, banking, ethics, West, Islam

\section{INTRODUCCIÓN}

Hace cuarentaaños, la peculiar concepción financiera de la banca islámica era considerada tremendamente utópica en Occidente. Efectivamente, era inimaginable concebir una actividad financiera sin la existencia de su alma mater, los intereses.

El Islamismo condena el cobro y el pago de todos los intereses porque los considera nefastos a la convivencia social y a la libertad del ser humano. En el período pre-islámico, las deudas pecuniarias impagadas convertían el deudor en esclavo del acreedor.

El profeta Mahoma, en la etapa inicial de conformación de la comunidad islámica (umma), no podía aceptar este peligro, puesto que la consolidación de la nueva religión y su propagación por otros territorios dependían fuertemente de la cohesión social.

El actual rechazo social hacia las especulaciones financieras ( $y$, de modo general, hacia el sistema bancario occidental), ha impulsado cierto protagonismo a la banca islámica, especialmente entre los musulmanes residentes en Reino Unido. Sus principios proclaman la responsabilidad, la transparencia y la moderación en las transacciones financieras.

Aunque el surgimiento de la banca islámica es relativamente reciente ${ }^{1}$, sus principios rectores han sido establecidos por el Corán y aceptados por la ummadesde siempre.La perspectiva ética de las finanzas está basada en el

\footnotetext{
${ }^{1}$ El año 1976 marca el resurgimiento de las finanzas islámicas con la celebración de la llegada del siglo XV del calendario muslímico (Hégira).
} 
Corán y en la Sunna, que buscan establecer la organización social y los comportamientos acordes con la voluntad de Alá. En este sentido, la equidad es un factor central. La distribución injusta de la riqueza debe ser evitada, así como la riqueza generada por la especulación. La idea es fomentar una economía real de carácter comercial.

\section{VERSÍCULOS ISLÁMICOS DE PROHIBICIÓN DEL INTERÉS}

La prohibición de la riba (que incluye el interés) existe porqué desvirtuaría la idea de justicia atribuida a Dios. Existendistintos versículos del Corán que establecen de forma absoluta y sin ambigüedades esa prohibición ${ }^{2}$ :

Versículo 275:

Quienes usurean no se levantarán sino como se levanta aquél a quien el Demonio ha derribado con sólo tocarle, y eso por decir que el comercio es como la usura, siendo así que Alá ha autorizado el comercio y prohibido la usura.

Quien exhortado por su Señor renuncie conservará lo que haya ganado. Su caso está en manos de Alá. Los reincidentes, ésos serán los condenados al Fuego y en él permanecerán para siempre.

Versículo 276:

2 Siddiqui, Shahid Hasan (2001). Islamic banking: true modes of financing. New Horizon, 109, 15-20.
Alá hace que se malogre la usura, pero hace fructificar la limosna. Alá no ama a nadie que sea infiel, pertinaz, pecador.

Versículo 278:

¡Creyentes! ¡Temed a Alá! ¡Y

renunciad a los provechos pendientes de la usura, si es que sois creyentes!

El interés está prohibido porque conlleva a injusticias, algo intolerable para el Islam. Además, hiere al principio de distribución equitativa de la riqueza mediante el trabajo ${ }^{3}$.

Maurer $(2005)^{4}$ señala que el Islam no desea privar al hombre de su búsqueda de bienestar económico, sino prohibir las actividades consideradas destructoras de valores morales (haram), como las transacciones relacionadas con bebidas alcohólicas, tabaco, juegos y casinos, pornografía o armas.

El Islamseñala el esfuerzo y el trabajo como los elementoslegitimadoresde la creación y acumulación de la riqueza, no la especulación financiera o la asignación de recursos para actividades degradantes del ser humano.Rahman\&Rahim $\quad(2007)^{5}$ comentan que la riqueza generada legítimamente no debe ser, bajo la

\footnotetext{
${ }^{3}$ La mayoría de los principios éticos y el sentido común también son observados en otras religiones.

4 Maurer, Bill (2005). Mutual life, limited: Islamic banking, alternative currencies, lateral reason.Princeton UniversityPress.

${ }^{5}$ Rahman, Abdul Rahim Abdul \& Rahim, Abdul (2007).Islamic microfinance: a missing component in Islamic banking.KyotoBulletin of IslamicAreaStudies, 1(2), 38-53.
} 
perspectiva islámica, despilfarrada, inutilizada o acaparada de modo insensato.

\section{EL DINERO NO DEBE GENERAR MÁS DINERO}

La finalidad del zakat, la "limosna obligatoria" $(2,5 \%$ de los beneficios anuales), uno de los pilares del Islam, es reducir la acumulación de riqueza disociada del esfuerzo, del trabajo y del bienestar general de la sociedad y, muy particularmente, de sus sectores más carentes y desfavorecidos.

Para el Islam, el dinero no debe generar más dinero (el opuesto es la máxima de los inversionistas y la banca convencional). El dinero, en otras palabras, no puede ser considerado una fuente legítima de creación o acumulación de riqueza, como en las típicas transacciones financieras occidentales. Para el Islam, la fuente primaria de la riqueza debe ser el esfuerzo y el trabajo ${ }^{6}$, no la rentabilidad de una asignación de recursos más o menos exitosa.

El-Gamal (2006) ${ }^{7}$ señala que eso no debe ser interpretado como un rechazo a la riqueza obtenida, por ejemplo, mediante herencia, donación o caridad. No obstante, para estar en conformidad con el Islam, el beneficiario deberá esforzarse para administrarla de acuerdo con los principios éticos islámicos.

\footnotetext{
${ }^{6}$ Están eximidos los discapacitados y enfermos que no pueden trabajar.

${ }^{7} \mathrm{El}-\mathrm{Gamal}$, Mahmoud A. (2006).Islamic finance: Law, economics, and practice.Cambridge UniversityPress.
}

Eso significa que una herencia no debe ser depauperada. Al contrario, el creyente debe utilizarla para perseguir un ingreso periódico que derive de su propio esfuerzo y trabajo. Caso contrario, el zakat consumiría esa riqueza gradualmente.

\section{LA COMPARTICIÓN DE RIESGOS EN LA BANCA ISLÁMICA}

El Corán (57:25) afirma que la injusticia es el camino hacia la destrucción de la sociedad. En términos financieros, se ha plasmado la regla de que la banca no puede volcar sus pérdidas sobre lasociedad. En términos empresariales, la banca asume el compromiso estatuido en la Sharia de compartir con el empresario los riesgos inherentes al negocio, además de destinar parte de los recursos que moviliza a la reducción de la pobreza, la generación de empleos y el fomento del autoempleo.

La compartición de riesgos entre banca y empresa (sustitutivo del tradicional préstamo occidental) implica la cogestión activa de la actividad empresarial. Ganancias y pérdidas son asumidas proporcionalmente a la participación de cada uno en el emprendimiento.

Aquí está una diferencia fundamental en relación a la banca occidental, que busca siempre asegurarse un beneficio, independientemente del resultado del proyecto. El eventual asesoramiento financierode la actividad empresarial, en Occidente, tiene por objeto el análisis de la viabilidad del negocio para efectos de evaluacióndel riesgo de 
impago por el tomador del préstamo. No asume la banca el rol de cogestora capaz de asumir las pérdidas de la actividad del prestatario.

Como bien asevera Siddiqi $(1983)^{8}$, las finanzas islámicas no permiten la especulación sobre bienes, activos o deudas ficticias. Tampoco admite la creación de deudas mediante el otorgamiento de préstamos directos por una entidad financiera o la venta de deudas, como suele ser habitual en las operaciones de mercado.Para eso, fija ciertas condicionesque deben ser escrupulosamente observadas, bajo pena de nulidad de la transacción:

- El activo (objeto de venta o del otorgamiento en leasing)debe ser real: esta obligatoriedad elimina la mayor parte de los derivados financieros, que tanto daño ocasionan a la sociedad cuando son mal gestionados e incurren en perjuicios.

- La banca debe tener la propiedad y posesión legítima de los activos: es una forma de presionarla a compartir el riesgo y a evitar las potencialmente peligrosas ventas en descubierto,tan nefastas para la economía(venta a plazo de valores que aún no se tienen, para recomprarlos en el futuro por un precio inferior). Las únicas excepciones contempladas en la Sharia son la istisna y el salam, en que se

\footnotetext{
${ }^{8}$ Siddiqi, Muhammad Nejatullah (1983). Issues in Islamic banking.The Islamic Foundation, Leicester.
}

debe pagar previamente para la adquisición o fabricación del producto(Usmani,2005) ${ }^{9}$

\section{- La transacción comercial o} financiera debe ser real: el propósito es impulsar la banca a actuar con cautela en el momento de evaluar los riesgos crediticios, reduciendo su concesión desmesurada (recomendación plasmada hace varios años en los acuerdos de Basilea, para evitar la creación de "burbujas especulativas"), además de reducir el volumen y el valor de las transacciones.

Estos son los elementosobjetivos. Paralelamente, existen elementos subjetivos como la intención de las partes en la operación. El propósito no debe ser el enriquecimiento sino la intención de dar y recibir un bien o un servicio.

\section{MECANISMOS DE ÉTICA ISLÁMICA: FINANCIACIÓN}

La falta de ética financiera en muchos países occidentales se prende, entre otras razones, al hecho de que la sociedad incentiva fuertemente el consumo. La banca cumple un rol importante, al promoverese consumo desenfrenado mediante la expansión exagerada del crédito en tiempos de

\footnotetext{
${ }^{9}$ Usmani, MaulanaTaqi (2005). Salam and Istisna.Online publication by accountancy. com. pk.Recuperado de http://islamicdatabase.org/sites/default/files/is lam_salam_istisna.pdf
} 
bonanza económica. Esta es la lógica del capitalismo.

En los países islámicos, al contrario, las transacciones impulsan la economía real, no las ingenierías financieras con sus meandros de dudosa ética (lo que, por un lado, acaba por ralentizarel desarrollo del propio sistema bancario, que crece mayormente en función de sus cuestionables operaciones). De cualquier modo, la mayor cautela de la entidad sobre la apreciación de los riesgos inherentes a la concesión de crédito permite liberar recursos para la economía real, en la medida de sus necesidades y disponibilidad de recursos.

El tema de la financiación de los bancos islámicos merece atención, ya que utilizan el interesante sistema denominado "compra sindicada"(Aggarwal\&Yousef, 2000) ${ }^{10}$. Explico sucintamente el mecanismo:

Normalmente las deudas públicas son vendidas en subastas públicas $\mathrm{y}$ adquiridas por compradores de deudas (los inversores), que esperan recibir los intereses correspondientes a los bonos y letras adquiridas en función de la emisión a corto, medio y largo plazo. Los estados evidentemente prefieren pagar el menor interés posible, lo que significa que adjudican la deuda pública a los compradores que menor interés piden por prestar su dinero.

Con la sindicación, los inversores (otros bancos, fondos de inversión y fondos soberanos) envían órdenes directas a un pequeño grupo de entidades bancarias para que compren deuda pública, sin que tengan que participar de las subastas públicas habituales. Este procedimiento, que no encuentra restricción en la Sharia, también es habitual en el mercado financiero occidental.

Otro sistema de financiación es la participación de inversores islámicos en el accionariado de la entidad bancaria. Su autorización depende de previa aprobación por la importante Academía Islámica Fiqh, creada por decisión de la Organización de la Conferencia Islámica en 1974 (inaugurada en 1981) y con sede en Yeddah, Arabia Saudí(Sole, 2007) ${ }^{11}$.Existe más de un centenar de fondos privados islámicos.

\section{NEGOCIOS ISLÁMICOS}

Aproximadamente dos tercios de los negocios vinculados con las finanzas islámicas se encuentran en los países del Consejo de Cooperación para los Estados Árabes del Golfo (Bahréin, Kuwait, Omán, Catar, Arabia Saudí y los Emiratos Árabes Unidos). Otros países en que las finanzas islámicas también están presentes con intensidad son Egipto, Indonesia, Malasia, Pakistán y Turquía. El centro de todos ellos es Bahréin. Fuera del mundo musulmán, Londres constituye el mayor centro de finanzas islámicas del mundo.

\footnotetext{
${ }^{11}$ Sole, Mr Juan (2007).Introducing Islamic Banks into Coventional Banking Systems (EPub) (No. 7-175).International Monetary Fund.

${ }^{10}$ Aggarwal, RajeshK., \& Yousef, Tarik (2000).Islamic banks and investment financing.Journal of money, credit and banking, 93-120. 
Es importante observar que ni todos los países con mayoría religiosa musulmana ofrecen al mercado únicamente productos basados en los principios, reglas y ética islámica. Malasia, por ejemplo, es un país donde ambos sistemas coexisten.

Amin\& Isa $(2008)^{12}$ señalan que en ese país operan bancos comerciales convencionales, bancos de inversión y diversas otras entidades financieras similares a de los países occidentales. Los productos financieros lanzados en el mercado malasio por esas empresas compiten con aquellos ofertados específicamente para la población musulmana (que debe seguir las reglas y los principios éticos de laSharia).

Sin embargo, como advierte Samad $(2004)^{13}$, la regulación financiera en ese país permite que mismo los bancos de corte occidental lancen divisiones especiales para captar los clientes musulmanes. Así, acaban competiendo, con otras reglas y con otros principios, con el Bank Mualmalat Malaysia y Bank Islam Malaysia.Por encima de todos ellos está el Banco Central de Malasia (Bank Negara Malaysia) que posee un consejo asesor de directorio Sharia cuya función principal es determinar las reglas que promuevan la

\footnotetext{
${ }^{12}$ Amin, Muslim\& Isa, Zaidi (2008).An examination of the relationship between service quality perception and customer satisfaction: a SEM approach towards Malaysian Islamic banking.International Journal of Islamic and Middle Eastern Finance and Management, 1(3), 191-209.

${ }^{13}$ Samad, Abdus (2004). Performance of Interest-free Islamic banks vis-à-vis Interestbased Conventional Banks of Bahrain.International Journal of Economics, Management and Accounting, 12(2), 85-103.
}

uniformidad de productos y servicios acordes con la ética financiera islámica para todo banco que los oferte al público, lo que incluye bancos islámicos y bancos convencionales (autorizados a funcionar en el país) con divisiones de productos especialmente dirigidos a la comunidad musulmana ${ }^{14}$.

En lo que concierne a Reino Unido, según Mashayekhi, Hicks, Rahman\&Ravalia $(2007)^{15}$, hace ya varios años que Londres se ha convertido en el centro de la banca para Oriente Medio y Asia. Muchos de los bancos islámicos del Golfo Pérsico tienen la administración de su tesorería y de los fondos de inversión islámica en la City.

El volumen con que operan los bancos islámicos ha ultrapasadolos 2 billones de dólares en la actualidad,según cálculos proyectados a partir de losestudios realizados por Khamis, AlHassan\&Oulidi (2010) ${ }^{16}$. Además, según los especialistas, las finanzas islámicas tienen un ritmo de crecimiento sostenido de 10 a $30 \%$ al año. Muchos gobiernos están interesados en atraer ese dinero para reactivar sus problemáticas economías. Como lo harán, dependerá del cuanto estén los bancos dispuestos a crear

\footnotetext{
${ }^{14}$ Malaysia, Bank Negara (2010).Shariah governance framework for Islamic financial institutions.Bank Negara Malaysia, Kuala Lumpur.

${ }^{15}$ Mashayekhi, A., Hicks, R., Rahman, A., \&Ravalia, A. (2007).Islamic finance in the UK: regulation and challenges (Vol. 9).London: Financial Services Authority.

${ }^{16}$ Khamis, May Y., Al-Hassan, Abdullah, \&Oulidi, Nada (2010). The GCC banking sector: Topography and analysis, 10-87.International Monetary Fund.
} 
divisiones islámicas y a ofrecer productos para potenciales clientes de la comunidad musulmana, basados en los principios éticos del Corán y de la Sunna.

El perfil de los bancos occidentales, con sus operaciones poco transparentes y su apuesta por las actividades lucrativas, sin tomar en cuenta, escrupulosamente, el fondo ético (ético-religioso, en este caso) de los negocios, no es compatible con el principio de exclusión de los intereses para generar capital, propio del sistema financiero islámico.

De cualquier modo, tal como ocurrió en Londres, es posible que la visión estratégica de algunos banqueros acabebuscando la armonía de ambos sistemas bajo el denominador común de los beneficios económicos. Sería conveniente, en este caso, que cuenten con un cuerpo de asesores especializados en la Sharia para que la oferta tenga real penetración en la comunidad musulmana. Los bancos islámicos suelen contar con un comité de asesores religiosos cuya función consiste en analizar la compatibilidad de los instrumentos y servicios con las reglas del Corán y de la Sunna. Esos comités, además, al cierre del ejercicio fiscal, deben emitir una opinión religiosa de carácter ético-financiero sobre las actividades realizadas por el banco.

\section{PRODUCTOS FINANCIEROS ISLÁMICOS}

Como era de esperar, en sus pocos años de actividad, la banca islámica ha desarrollado productos que generan rendimientos aceptables para los inversores aunque, por los principios religiosos, excluyan las actividades consideradas denigrantes para el ser humano.

Jaufeerally (2011) ${ }^{17}$, en reciente estudio, señala que el trading de commodities, el leasing, las operaciones de bienes raíces y los productos de la denominada "línea islámica" (préstamos islámicos, tarjetas de crédito islámicas, derivados financieros islámicos y bonos islámicos) constituyen las áreas más activas de la banca islámica actual. La "línea islámica" sigue estrictamente las directrices éticas establecidas en el Corán, estando desde hace años disponibles los bonos en los Estados Unidos de América (Chiu, Newberger\&Paulson, 2005).

SegúnShubber (2009) ${ }^{18}$, existen dos grandes categorías de instrumentos financieros en los países islámicos:

- Los que generan un retorno financiero variable (Musharakah y Mudarabath):

a) El Musharakah es una sociedad de inversión que se

caracteriza por dos elementos básicos: 1) la compartición de las ganancias se pacta por adelantado, 2) las pérdidas nunca pueden superar el monto de la inversión.

\footnotetext{
${ }^{17}$ Jaufeerally, Reza Zain (2011). Islamic Banking and Responsible Investment: Is a Fusion Possible?.Responsible Investment in Times of Turmoil, 151-163. Springer Netherlands.

${ }^{18}$ Shubber, Kadom (2009). Usury laws, Islamic finance and the credit crunch.International Journal of Islamic and Middle Eastern Finance and Management, 2(4), 31-43.
} 
b) El Mudarabahtes un contrato de asesoría financiera en que las ganancias relacionadas con las inversiones son compartidas por el cliente y el banco. La responsabilidad del asesor por las eventuales pérdidas no existe (salvo que tenga obrado de mala fe). Caso ocurran, deberá ser suportada por el cliente. El banco tampoco cobrará cualquier valor por la administración de la cartera (lo hará si la inversión presenta retorno).

- Los que generan un retorno financiero fijo, más acorde con las finanzas islámicas (Ijara):

a) La Ijara: corresponde a la compra de un bien por el banco, según la indicación del cliente, para luego realizar un lease-back por un período de tiempo determinado.

b) LaIjara-wa-Iqtina: es similar al contrato anterior, pero con opción de compra al finalizar el contrato.

Habbas $(2008)^{19}$ y Ali $(2008)^{20}$, por su vez, señalan la expansión del Susuk, un instrumento equivalente a la venta de bonos en los bancos occidentales. La diferencia es que los bancos islámicos emisores en vez de vender la deuda, venden una parte de su activo, lo que permite al comprador alquilarla. Además, los tomadores del crédito, al ser tratados como accionistas (el derecho bancario islámico exige que la

\footnotetext{
${ }^{19}$ Habbas, Sam (2008). Welcome Change for Sukuks.Int'I Fin. L. Rev., 27, 58-75.

${ }^{20}$ Ali, Rahail (2008). Islamic Finance: a practical guide.West Yorkshire: Emerald Group Publishing Limited.
}

banca comparta tanto riesgos como ganancias con eses tomadores), obtienen capital en virtud de las propias ganancias del banco.

Por último,Gundogdu $(2009)^{21}$ comenta que elinstrumentoconocido por Murabahafunciona como un sustitutivo ético del crédito con intereses, largamente utilizado en Occidente. Con ese instrumento financiero islámico, el cliente del banco, interesado en adquirir un bien, en vez de solicitar un crédito, encarga al banco de comprar ese bien. Una vez adquirido por el banco, ese lo revende de forma diferida, a plazos sin intereses.

Mismo durante la crisis - y quizá en función de ella, cuando se ha incrementado el número de personas críticas con la falta de ética o valores del sistema capitalista en general y de la banca, en particular - se ha incrementado los negocios en la banca islámica.

\section{CONCLUSIONES}

La Sharia señala un camino éticamente posible para la actividad financiera internacional. Se puede obtener prácticamente los mismos niveles de financiación y rentabilidades sin volcar sobre la sociedad pérdidas motivadas por transacciones opacas $\mathrm{y}$, muchas veces, a margen de la legalidad.

Actualmente los mayores bancos occidentales, como Deutsche Bank,

\footnotetext{
${ }^{21}$ Gundogdu, Ahmet Suayb (2009). 2-Step Murabaha as an alternative resource mobilization tool for Islamic banks in the context of international trade.International Journal of Monetary Economics and Finance, 2(3), 286-301.
} 
HSBC o Citigroup, están entrando en el negocio de la banca islámica, interesados especialmente en la riqueza del Oriente Medio generada por el alto precio del petróleo de los últimos años.

De cualquier forma, las grandes fortunas de esos países, después de los eventos de 11 de septiembre de 2001, para evitar cuestionamientos e investigaciones incómodas, optaron por movilizar su dinero desde Europa y EE.UU. hacia Asia u otros países del Oriente Medio. En medio de todo ese movimiento, hay quien vislumbre la oportunidad de que ese dinero sea aprovechado por España (Rodríguez, 2012) ${ }^{22}$ o, específicamente, por Catalunya (Carrió, 2011) ${ }^{23}$, pero eso ya es otro tema.

\section{REFERENCIAS BIBLIOGRÁFICAS}

Aggarwal, Rajesh K., \& Yousef, Tarik (2000).Islamic banks and investment financing.Journal of money, credit and banking, 93-120.

Ali, Rahail (2008). Islamic Finance: a practical guide.West Yorkshire: Emerald Group Publishing Limited.

Amin, Muslim \& Isa, Zaidi (2008).An examination of the relationship between service quality perception and customer satisfaction: a SEM approach towards Malaysian

Islamic

22 Rodríguez, Almudena Kessler (2012). Finanzas Islámicas: una oportunidad para España. Boletín económico de ICE, Información Comercial Española, (3022), 25-34.

${ }^{23}$ Carrió, Robert Tornabell (2011). La banca islàmica: una oportunitat de finançament per a Catalunya. Via. Valors, idees, actituds: revista del Centre d'Estudis Jordi Pujol, (17), 48-56.
banking.International Journal of Islamic and Middle Eastern Finance and Management, 1(3), 191-209.

Carrió, Robert Tornabell (2011). La banca islàmica: una oportunitat de finançament per a Catalunya. Via. Valors, idees, actituds: revista del Centre d'Estudis Jordi Pujol, 17, 48-56.

El-Gamal, Mahmoud A. (2006).Islamic finance: Law, economics, and practice.Cambridge University Press.

Gundogdu, Ahmet Suayb (2009). 2-Step Murabaha as an alternative resource mobilization tool for Islamic banks in the context of international trade.International Journal of Monetary Economics and Finance, 2(3), 286-301.

Habbas, Sam (2008). Welcome Change for Sukuks.Int'l Fin. L. Rev., 27, 58-75.

Jaufeerally, Reza Zain (2011). Islamic Banking and Responsible Investment: Is a Fusion Possible?.Responsible Investment in Times of Turmoil, 151163. Springer Netherlands.

Khamis, May Y., Al-Hassan, Abdullah, \&Oulidi, Nada (2010). The GCC banking sector: Topography and analysis, 10-87.International Monetary Fund.

Malaysia, Bank Negara (2010).Shariah governance framework for Islamic financial institutions. Bank Negara Malaysia, Kuala Lumpur.

Mashayekhi, A., Hicks, R., Rahman, A., \&Ravalia, A. (2007).Islamic finance in the UK: regulation and challenges (vol. 9).London: Financial Services Authority. 
Maurer, Bill (2005). Mutual life, limited: Islamic banking, alternative currencies, lateral reason.Princeton University Press.

Rahman, Abdul Rahim Abdul \& Rahim, Abdul (2007).Islamic microfinance: a missing component in Islamic banking.Kyoto Bulletin of Islamic Area Studies, 1(2), 38-53.

Rodríguez, Almudena Kessler (2012). Finanzas Islámicas: una oportunidad para España. Boletín económico de ICE, Información Comercial Española, (3022), 25-34.

Samad, Abdus (2004). Performance of Interest-free Islamic banks vis-à-vis Interest-based Conventional Banks of Bahrain.International Journal of Economics, Management and Accounting, 12(2), 85-103.

Shubber, Kadom (2009). Usury laws, Islamic finance and the credit crunch.International Journal of Islamic and Middle Eastern Finance and Management, 2(4), 31-43.

Siddiqi, Muhammad Nejatullah (1983). Issues in Islamic banking. The Islamic Foundation, Leicester.

Siddiqui, Shahid Hasan (2001). Islamic banking: true modes of financing.New Horizon, 109, 15-20.

Sole, Mr Juan (2007).Introducing Islamic Banks into Coventional Banking Systems (EPub) (No. 7175).International Monetary Fund.

Usmani, MaulanaTaqi (2005). Salam and Istisna.Online publication by accountancy. com. pk. Recuperado de http://islamicdatabase.org/sites/default/f iles/islam_salam_istisna.pdf 